Q $10 \begin{aligned} & \mathrm{http}: / / \mathrm{dx} . \text { doi.org/10.21611/qirt.2010.141 } \\ & 10^{\text {th }} \text { International Conference on Quantitative InfraRed Thermography }\end{aligned}$

\title{
AN EXPERIMENTAL STUDY OF SUB-SURFACE DEFECTS DETECTION OF BAKELITE USING ACTIVE MODE THERMOGRAPHY
}

\author{
M. Z. Umar*, A. R. Hamzah* \& V. Vavilov** \\ *Non-Destructive Testing Group, Malaysian Nuclear Agency, Bangi, 43000 Kajang, Selangor, Malaysia, \\ zaki@nuclearmalaysia.gov.my; razak_hamzah@nuclearmalaysia.gov.my \\ **Tomsk Polytechnic University, 7 Savinykh St., Tomsk, 634028 Russia, \\ innovation@mail.tomsknet.ru
}

\begin{abstract}
Passive mode of Infrared Thermography (IRT) has proven to be an effective and reliable technique for condition monitoring and preventive maintenance purposes. However, active mode of IRT is considerably new for Malaysian industries in term of measuring defect in Non-Destructive Testing (NDT) activities. For the project discussed herein, active mode of IRT, specifically one -sided Pulsed Thermal (PT) method was used to detect several simulated sub-surface defects in eight pieces of bakelite- a non-metal and low conductive material. Heating of samples were done using $30 \mathrm{kWatt}$ adjustable halogen lamps while infrared (IR) images of samples were recorded using THV 550 IR camera. These IR images also called thermogram were then analysed using Thermofit ${ }^{\mathrm{TM}}$ Pro software to obtain the Maximum Absolute Differential Temperature Signal value, $\Delta T_{\max }$ and the time of its appearance, $\tau_{\max }(\Delta T)$. The results demonstrate that the method has capability to detect all simulated defects where the sensitivity of the approached method is proportionately related to the size of defect diameter if the defects are at the same depth and at the same time it is inverserly related with the depth of defect if the defects have similar diameter size. The result also has a good agreement with computer simulation used ThermoCal-2D software. As a conclusion the study has confirmed the ability and potential of active mode thermography as a technique for sub-surface defects detection in non-metal or low conductive material.
\end{abstract}

Keywords: infrared thermography, active mode thermography, pulsed thermal, sub-surface defects 